\title{
Evolution of Calcite Growth Morphology in the Presence of Magnesium: Implications for the Dolomite Problem
}

\author{
Mina Hong ${ }^{1}$, Jie $\mathrm{Xu}^{2}$, and Henry H. Teng ${ }^{1 *}$ \\ ${ }^{I}$ Department of Chemistry, The George Washington University, Washington, DC 20052 \\ ${ }^{2}$ Department of Geoscience, Virginia Polytechnic Institute, Blacksburg, VA 24061
}

\begin{abstract}
The effect of magnesium on calcite growth morphology was known to occur as step rounding in some cases and surface segmentation in others. What remain unknown are the conditions for and the relations between the different effects, suggesting a lack of comprehensive understanding in the fundamental cause. Here we investigated the evolution of spiral hillock morphology on calcite cleavage surfaces in solutions with increasing $\mathrm{Ca}$ to $\mathrm{Mg}$ ratios and supersaturation levels using in situ atomic force microscopy. We isolated the effects of $\mathrm{Mg}$ and saturation by conducting experiments under conditions of constant $\mathrm{pH}$, ionic strength, and $\mathrm{Ca}^{2+} / \mathrm{CO}_{3}{ }^{2-}$. Our results revealed three types of morphological variations, ranging from step rounding in one direction (type I), to all directions (type II), and finally to a mosaic-like surface segmentation associated with monolayer buckling and step bunching (type III). These results suggest that the effect of magnesium on calcite growth depends upon multiple parameters including the concentration of $\mathrm{Mg}$ in solution, the step speed, as well as the extensiveness of $\mathrm{Mg}$ for Ca substitution in calcite lattice. We propose that the morphological variation may be understood by a model that takes into consideration of (1) the lifespan and flux size of $\mathrm{Mg}$ ions at kinks in comparison to step kinetics, and (2) the diffusion and alignment of point defects created by the substitution of $\mathrm{Mg}$ for $\mathrm{Ca}$ in the crystal lattice. Stress calculations show that the maximum amount of Mg which calcite lattice can sustain before plastic deformation is $\sim 40 \%$, suggesting that lattice stress due to the mismatch between $\mathrm{MgCO}_{3}$ and $\mathrm{CaCO}_{3}$ is likely the ultimate cause for the difficulty of ambient condition dolomite crystallization.
\end{abstract}

* To whom inquiries should be addressed (Phone: 202-994-0112, Email: hteng@gwu.edu) 


\section{INTRODUCTION}

The incorporation of magnesium ions into calcium carbonate minerals is a critical subject to understanding the 'dolomite problem', biomineralization processes, and, more recently, the foraminiferal $\mathrm{Mg} / \mathrm{Ca}$-paleothermometry (e.g. [Lippmann, F. 1973; Berner, R. A. 1975; Bischoff, W. D., Bishop, F. C. et al. 1983; Mucci, A. and Morse, J. W. 1983; Lear, C. H., Rosenthal, Y. et al. 2002; Barker, S., Greaves, M. et al. 2003; Gayathri, S., Lakshminarayanan, R. et al. 2007; Evans, D. W., Muller-Loennies, S. et al. 2012; Xu, J., Yan, C. et al. 2013]). In a broad sense, the presence of $\mathrm{Mg}$ in the lattice of $\mathrm{CaCO}_{3}$ phases renders three types of effects on the mineralization of calcium carbonate. Firstly, many studies indicated that $\mathrm{Mg}$ reduces the thermodynamic stability of calcite [Busenberg, E. and Plummer, L. N. 1989; Konigsberger, E. and Gamsjager, H. 1992; Davis, K. J., Dove, P. M. et al. 2000; Davis, K. J., Dove, P. M. et al. 2004; Kulik, D. A. 2006]. This decrease is believed to be caused by the introduction of disorder [Berner, R. A. 1975; Mucci, A. and Morse, J. W. 1983] and lattice strain [Glodsmith, J.R. and Graf, D. L. 1958; Goldsmith, J. R., Graf, D. L. et al. 1961; Althoff, P. L. 1977; Bischoff, W. D., Bishop, F. C. et al. 1983; Paquette, J. and Reeder, R. J. 1990] in the calcite structure due to the size difference between $\mathrm{Ca}^{2+}(\mathrm{r}=1.14 \AA)$ and $\mathrm{Mg}^{2+}(\mathrm{r}=0.86 \AA)$ [Shannon, R. D. 1976]. Measurements of calcite step propagation rates in the presence of $\mathrm{Mg}$ demonstrated that the incorporation of $\mathrm{Mg}$ as an impurity increases the local solubility at kinks [Davis, K. J., Dove, P. M. et al. 2004; Wasylenki, L. E., Dove, P. M. et al. 2005; Stephenson, A. E., DeYoreo, J. J. et al. 2008], in support of the thermodynamic consideration. Secondly, a plethora of experimental work documented the significant retardation of $\mathrm{Mg}$ ions on the growth kinetics of $\mathrm{CaCO}_{3}$ [Davis, K. J., Dove, P. M. et al. 2000; Davis, K. J., Dove, P. M. 
et al. 2004; Wasylenki, L. E., Dove, P. M. et al. 2005; Stephenson, A. E., DeYoreo, J. J. et al. 2008; Astilleros, J. M., Fernandez-Diaz, L. et al. 2010]. Compared to $\mathrm{Ca}^{2+}, \mathrm{Mg}^{2+}$ is $24.56 \%$ smaller, leading to a 1.76 times higher charge density and, in turn, a considerably stronger hydration. The presence of such a strong water shell is suggested to increase the kinetic barrier for calcite nucleation and growth when magnesium is adsorbed onto mineral surfaces [Lippmann, F. 1973; Loste, E., Wilson, R. M. et al. 2003; De Yoreo, J. J., Zepeda-Ruiz, L. A. et al. 2009]. A step pinning model in which the binding of $\mathrm{Mg}^{2+}$ ions to calcite surface edges prevents the attachment of $\mathrm{Ca}^{2+}$ at kink sites [De Yoreo, J. J. and Vekilov, P. G. 2003; Arvidson, R. S., Collier, M. et al. 2006; Xu, M. and Higgins, S. R. 2011] provides a very reasonable explanation for such a kinetic effect.

The third widely reported magnesium effect is the modification of calcite growth morphology. Earlier observations focused primarily on the more rounded rhombohedral appearance of calcite crystals grown in the presence of $\mathrm{Mg}$ [Davis, K. J., Dove, P. M. et al. 2000; Davis, K. J., Dove, P. M. et al. 2004; Stephenson, A. E., DeYoreo, J. J. et al. 2008; Zhang, F. F., Yan, C. et al. 2013]. Given and Wilkinson [1985] hypothesized that that morphological change results chiefly from the supply rate of carbonate ions instead of $\mathrm{Mg}$ effect. However, later studies using differential interference contrast (DIC) imaging technique [Northrup, P. A. and Reeder, R. J. 1994; Tang, Y. Z., Elzinga, E. J. et al. 2007] revealed an uneven distribution of $\mathrm{Mg}$ on calcite growth surfaces with higher

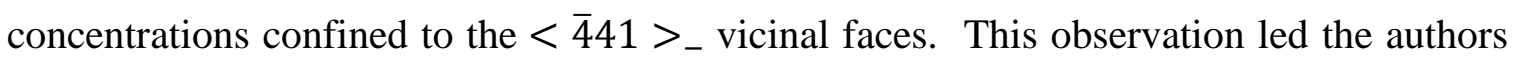
to suggest that, based upon the size and geometric differences in kink sites at steps of different orientations on calcite surfaces, the smaller $\mathrm{Mg}^{2+}$ prefers to enter the smaller and more closed acute steps [Paquette, J. and Reeder, R. J. 1990; Reeder, R. J. 1996]. This 
hypothesis was later supported by in situ atomic force microscopy (AFM) data [Davis, K. J., Dove, P. M. et al. 2000; Davis, K. J., Dove, P. M. et al. 2004; Wasylenki, L. E., Dove, P. M. et al. 2005; Stephenson, A. E., DeYoreo, J. J. et al. 2008; Astilleros, J. M., Fernandez-Diaz, L. et al. 2010; Sethmann, I., Wang, J. W. et al. 2010; King, H. E., Satoh, H. et al. 2013] which showed that Mg incorporation at calcite growth steps is indeed crystallographic direction specific. It was further suggested that the preferential incorporation of $\mathrm{Mg}$ in acute steps hinders the growth kinetic and weakens the surface energetic control on step orientations, and ultimately leads to the rounding of growth steps [Falini, G., Gazzano, M. et al. 1994; Zhang, Y. P. and Dawe, R. A. 2000; Meldrum, F. C. and Hyde, S. T. 2001; Davis, K. J., Dove, P. M. et al. 2004]. A careful examination of the literature data, however, reveals a less discussed observation that shows that the directional development of step rounding appears to be dependent on solution supersaturation (with respect to calcite): whereas significant rounding occurs in the acute side at low supersaturation conditions, step deformation develops in both $\langle\overline{4} 41\rangle_{+}$and $<\overline{4} 41>_{\text {_ }}$ when supersaturations rise to result in growth hillocks elongated along the cglide [Davis, K. J., Dove, P. M. et al. 2000; Davis, K. J., Dove, P. M. et al. 2004; Wasylenki, L. E., Dove, P. M. et al. 2005; Stephenson, A. E., DeYoreo, J. J. et al. 2008].

Step rounding was the prevalent morphological change known for the $\mathrm{Mg}$ effect until recently, when a different growth feature - surface segmentation - was reported [Astilleros, J. M., Fernandez-Diaz, L. et al. 2010; Sethmann, I., Wang, J. W. et al. 2010; King, H. E., Satoh, H. et al. 2013]. This type of morphology is characterized by the development of a mosaic-like feature where individual tiles take on a rhombic appearance following the original cleavage directions of calcite. The interpretation to this 
morphological development invoked lattice strain derived from the mismatch between $\mathrm{MgCO}_{3}$ and $\mathrm{CaCO}_{3}$ structures [Astilleros, J. M., Fernandez-Diaz, L. et al. 2010; Sethmann, I., Wang, J. W. et al. 2010; Pimentel, C., Pina, C. M. et al. 2013]. For example, [Sethmann, I., Wang, J. W. et al. 2010] combined AFM observations with molecular dynamic simulations and suggested that strain energy may be released by the formation of disordered linear zones cutting through monolayers on calcite growing surfaces to cause a surface bulge. [Pimentel, C., Pina, C. M. et al. 2013] suggested the generation of screw dislocations at the initial buildup of lattice strain as evidenced by growth spirals on individual tiles, and ultimately the formation of "sub-nano step" along the original step direction when crystal fails to sustain the internal stress.

Suffice it to say that these findings depict a complex morphological effect of $\mathrm{Mg}$ on calcite growth and suggest that a clear understanding of the conditions under which specific morphology manifests and of how the different morphologies are related is still missing. In the present work we attempt to address these issues by conducting calcite growth experiments under conditions of varying supersaturation and $\mathrm{Mg}$ to Ca ratio in the solutions while maintaining $\mathrm{pH}$, ionic strength, and $\mathrm{C}_{\mathrm{Ca}^{2+}} / \mathrm{a}_{\mathrm{CO}_{3}^{2-}}$ constant. We postulate that the Mg effect depends not only on the level of Mg content in the solution but upon the step kinetics as well. In addition, we suspect that regional lattice strain buildup due to local accumulation of point defects formed by $\mathrm{Mg}$ substitution for $\mathrm{Ca}$ causes plastic deformation that ultimately leads to the inhibition of calcite growth.

\section{EXPERIMENTAL DETAILS}


Growth solutions were made by dissolving reagent grade $\mathrm{NaHCO}_{3}, \mathrm{CaCl}_{2}, \mathrm{NaCl}$ and $\mathrm{MgCl}_{2}$ (Sigma Aldrich) into deionized water (resistivity $18.2 \mathrm{~m} \Omega$ ). Solution $\mathrm{pH}(8.0)$, ionic strength $I S(0.1)$ and $a_{\mathrm{Ca}^{2+}} / a_{\mathrm{CO}_{3}^{2-}}$ (1.0) were fixed while the supersaturations of calcite and dolomite as well as $a_{M g^{2+}} / a_{C a^{2+}}\left(R_{M g / C a}\right)$ vary. Solution speciation calculations were performed by PHREEQC [Parkhurst, D. L. and Appelo, C. A. J. 1999] with the Davies equation [Davies, C. W. 1962] applied for activity correction. Supersaturation indexes for both calcite and dolomite are defined as follows:

$$
\begin{aligned}
\gamma_{\text {cal }} & =\log \frac{a_{\mathrm{Ca}^{2+}} a_{\mathrm{CO}_{3}^{2-}}}{K_{\text {Sp(calcite })}} \\
\gamma_{\text {dol }} & =\log \frac{a_{\mathrm{Ca}^{2+}} a_{\mathrm{Mg}^{2+}} a_{C \mathrm{CO}_{3}^{2-}}^{2}}{K_{\text {sp (dolomite })}}
\end{aligned}
$$

where $a_{i}$ is the activity of species $i$ and $K_{s p}$ is the solubility product (calcite $10^{-8.48}$ and dolomite $10^{-16.70}$ at $25^{\circ} \mathrm{C}$ ). Freshly cleaved calcite chips of optical-quality Iceland spar (Ward's Scientific, Chihuahua, Mexico) were used for in situ AFM fluid cell experiments where $\gamma_{c a l}$ varied from 0.5 to $1.2, \gamma_{\text {dol }}$ from 1.83 to 3.22, and $R_{M g / C a}$ from 1 to 7 (Fig. 1). AFM Images of calcite growing surfaces were collected by a a Nanoscope IIIc Scanning Probe Microscope (Digital Instruments, contact mode) while experimental solutions were continuously introduced in the cell by a syringe pump at a flow rate of $40 \mathrm{~mL} / \mathrm{h}$. Step growth rates were measured in both obtuse and acute directions, respectively if possible, on consecutive (alternating upward and downward scan directions) images from the changes in the angles bisecting two adjacent steps [De Yoreo, J. J., Land, T. A. et al. 1997].

\section{RESULTS}


Consistent with previous reports [Davis, K. J., Dove, P. M. et al. 2004; Wasylenki, L. E., Dove, P. M. et al. 2005; Zhang, F. F., Yan, C. et al. 2013], the presence of $\mathrm{Mg}^{2+}$ ions in growth solutions significantly retarded calcite monolayers propagation. For example, at $\gamma_{c a l}=0.5$, the introduction of $1.2 \mathrm{mM} \mathrm{Mg}$ solution induced an $85 \%$ decrease in calcite step speed within 20 seconds. In contrast to the sharply visible hindrance to step kinetics, changes in the morphology of the inherent rhombohedral growth hillocks appeared to be transitory and complex. Broadly speaking, three types of modified morphologies, depending upon the solution chemistry, manifested during our experiments. The first type (Fig. 2a) is characterized by step alteration confined chiefly to the acute side. Compared to the intact (or weakly affected) obtuse steps, changes in the acute orientation are featured by varied degrees of loss of step directions (i.e. rounding) and structures (i.e. uniform step spacing and homogenization of steps and terraces). Type I morphology develops primarily at low $\gamma_{c a l}$ or low $R_{M g / C a}$ conditions.

A tear-drop morphology (type II, Fig. 2b), where both the obtuse and the acute sides become roughened and rounded, emerges in association with a modest increase in $R_{M g / C a}$ and $\gamma_{c a l}$. In the cases where rounding is severe, the surface feature appears to completely lose the inherent rhombohedral frame as no clearly defined crystallographic directions are identifiable on the growth hillocks. Instead, the spirals become elongated parallel to the c-glide and evolve into a pseudo-oval shape with wider step spacing in the $\langle\overline{4} 41\rangle_{+}$directions, the only remaining feature of the original spirals.

A third type of morphology (Fig. 2c) featuring surface segmentation develops from type II and becomes dominated by continuous elevation of $\gamma_{c a l}$ and $R_{M g / C a}$; however, the minimal levels of $R_{M g / C a}$ and $\gamma_{c a l}$ required for the transition seem to be 
inversely related to one another. The fragmented surfaces are characterized by ridges with several tens of nanometers in height, constituting the boundaries of the 'mosaic-like' surface segments. Instead of rounding, these edges run along the original cleavage directions of $<48 \overline{1}>$ and $<\overline{4} 41>$ with occasional occurrences of the $<42 \overline{1}>$. The initial transition from type II to type III morphology appears to start at the acute sides instigated by a sudden rupturing of curved steps snapping into straight segments or when in-plan bulging develops across multiple terraces (Fig. 2d). Furthermore, despite no detectable movement in the ridges, monolayer nucleation and growth continue within each segment but stop at the boundaries (i.e. ridges) as if the steps hit a wall. A summary view of growth morphologies at each experimental solution chemistry conditions is given in Fig. 1.

\section{DISCUSSION}

Results from our experiments clearly show that the morphological effect of $\mathrm{Mg}$ on calcite growth is more complex than previously reported. More importantly, the results suggest that there is no single factor that dominates in controlling the morphology change; instead, multiple parameters, including $a_{\mathrm{Mg}^{2+}} / a_{\mathrm{Ca}^{2+}}$ and supersaturations, are collectively in play. Here we attempt to combine the various controls to offer a more comprehensive view for the role of $\mathrm{Mg}$ in calcite growth.

\section{Type I and II morphology}

Assuming the observed morphological variations result from the $\mathrm{Mg}$ effect, the development of type I morphology indicates selective adsorption/incorporation of $\mathrm{Mg}$ at the acute steps. Given the preference of $\mathrm{Mg}$ for the geometrically more closed and 
smaller sites at the $\langle\overline{4} 41\rangle$. steps [Paquette, J. and Reeder, R. J. 1995], the observed selectivity does not come as a surprise. In fact, the persistent development of Type I morphology in solutions with elevated $R_{M g / C a}$ (up to 7) at low $\gamma_{c a l}=0.5$ or at high calcite supersaturation $\left(\gamma_{c a l}=1.2\right)$ but low $R_{M g / C a}=0.5$ appears to indicate that the differences in kink sites in different crystallographic directions are the chief governing forces that direct the $\mathrm{Mg}$ effect regardless of step kinetics and the relative abundance of $\mathrm{Mg}$ in growth media.

The development of type II at conditions of higher $\gamma_{c a l}$ and $R_{M g / C a}$, however, calls into question this explanation. Type II morphology is characterized by $\mathrm{Mg}$ affecting both the acute and obtuse steps, and can be regarded simply as a strengthened Mg effect leading to the loss of directional preference for $\mathrm{Mg}$ adsorption/incorporation. If kink size and geometry are the sole controlling factors, increased surface coverage of $\mathrm{Mg}$ (i.e. higher $R_{M g / C a}$ in solutions) and growth rates (i.e. higher $\gamma_{c a l}$ ) should not alter the shape of obtuse steps. Experimental observations, on the contrary, showed the development of type II morphology when both $\gamma_{c a l}$ and $R_{M g / C a}$ go beyond 0.5. For example, transformation of type I to type II was observed when the calcite supersaturation was increased from 0.5 to 0.7 at $a_{M g^{2+}} / a_{C a^{2+}}=5$, or the $\mathrm{Mg}$ to Ca ratio went up from 3 to 5 at $\gamma_{\text {cal }}=0.7$ (Fig. 1), revealing the roles of both surface coverage and step kinetics in the morphological variation. The multifaceted effects cannot be fully accounted for by the conventional impurity theories. For example, in the equilibrium adsorption model [Botsaris, G.D., Mason, E. A. et al. 1967], it is assumed that the surface coverage of impurity particles depends fully upon the step propagation rate. At low supersaturation conditions when step growth is slow and new layers cannot rapidly sweep through the 
growth surfaces, impurity adsorption reaches maximal (i.e. equilibrium) value and, consequently, exerts the strongest effect. On the other hand, when the surface is quickly overlain by newly grown layers at high supersaturations, the impurity cannot adsorb effectively and the effect therefore should be weakened. Following this model, one should expect to see the strongest $\mathrm{Mg}$ effect at low supersaturation conditions, contradicting the experimental observations.

We propose that the $\mathrm{Mg}$ effect may be understood by considering the lifespan and flux size of $\mathrm{Mg}$ at kinks in comparison to step kinetics. Following the classical approach to step kinetics [Chernov, A. A. 1961], one can assume that the Mg attachment rate $\varpi$ at a step is a function that combines ion attachment frequency $f_{\mathrm{a}}$, the average lifetime $\tau$ of $\mathrm{Mg}$ ions at kinks, and the size of $\mathrm{Mg}$ flux $J$ near growth sites. The magnitude of $J$ (defined as $-D_{M g} \nabla_{M g}$ by Fick's Law where $D$ is the diffusion coefficient and $\nabla$ the concentration gradient) in the present study is directly proportional to the absolute population of $\mathrm{Mg}$ particles in the solution, but is also a function of $\gamma_{c a l}$ because it is constrained by the magnitude of $R_{M g / C a}$. Since calcium concentration in our experimental solutions (where $a_{C a^{2+}} / a_{C O_{3}^{2-}}$ was made to be unity) can be represented by $\left(10^{\gamma_{c a l}} K_{S p}\right)^{1 / 2}$, one can show that the size of $J$ for $\mathrm{Mg}$ is a function of $D_{M g} R_{M g / C a}\left(10^{\gamma_{c a l}} K_{s p}\right)^{1 / 2}$. Collectively, we have the relation

$$
\varpi=\phi\left[f_{a} \tau D_{M g} R_{M g / C a}\left(10^{\gamma_{c a l}} K_{s p}\right)^{1 / 2}\right]
$$

to predict the rate for $\mathrm{Mg}$ attachment at steps.

On the other hand, the classical crystal growth theory [Burton, W. K., Cabrera, N. et al. 1951; Chernov, A. A. 1961] predicts that the growth rate of monomolecular steps is positively correlated to supersaturation in the form of $v_{s}=\phi\left(a-a_{e}\right)$ where $\left(a-a_{e}\right)$ is 
the deviation of the solute activity $a$ from its equilibrium value $a_{e}$ [Chernov, A. A. 1961]. In our experimental system $a$ and $a_{e}$ are equivalent to $\left(10^{\gamma_{c a l}} K_{s p}\right)^{1 / 2}$ and $\left(K_{s p}\right)^{1 / 2}$, respectively. Inserting the two expressions into the classic step kinetic equation, one shows that step velocity in the present study may be estimated by

$$
v_{s}=\phi\left[\left(K_{s p}\right)^{1 / 2}\left(10^{1 / 2 \gamma_{c a l}}-1\right)\right]
$$

in the absence of the impurity effect.

In isotropic crystal systems where steps are identical in all directions, the effect of $\mathrm{Mg}$ on step morphology can be examined by simply comparing the relative size of $\varpi$ and $v_{s}$ : if $\varpi / v_{s}>1$, significant $\mathrm{Mg}$ adsorption/incorporation develops leading to step rounding; when $\varpi / v_{s}<1, \mathrm{Mg}$ adsorption/incorporation is trivial, and steps are not subject to the strong impurity effect and will maintain straight morphology. In an anisotropic system such as calcite, additional consideration on $\tau$ (the average lifespan of $\mathrm{Mg}$ at kinks) and the surface coverage of $\mathrm{Mg}$ at individual steps $\left(\Lambda_{i}\right.$ where $i$ is the direction with a longer $\tau$ ) is needed to understand the direction preference of $\mathrm{Mg}$ adsorption or incoporation. As long as $\Lambda_{i}<100 \%, \mathrm{Mg}$ will be preferentially incorporated into steps in direction $i$, otherwise the direction preference will diminish due to the saturation of $\mathrm{Mg}$ ions at the preferred steps.

In our experiments, the attachment frequency $f_{\mathrm{a}}$ and the $\mathrm{Mg}$ flux $J$ should, to a first order approximation, not differ significantly in different orientations because these two parameters are chiefly dependent on temperature and solution concentration, respectively. Such reasoning leaves the lifetime $\tau$ of $\mathrm{Mg}^{2+}$ at kinks to be the primary responsible factor for the step preference. Given the closer matching between $\mathrm{Mg}$ and the acute sites detailed by Paquette and Reeder [Reeder, R. J. and Paquette, J. 1989; Paquette, J. and 
Reeder, R. J. 1990], it is reasonable to assume $\tau_{-}>\tau_{+}$for calcite. As such, at conditions of low step velocity (e.g. low $\gamma_{c a l}$ ) where $\varpi / v_{s}>1$, step rounding in the acute directions should occur; any increase in $R_{M g / C a}$ will further augment the magnitude of $\varpi$ (Eq. 3), leading to an even stronger preferential adsorption/incorporation of $\mathrm{Mg}$ at the acute steps. This explains the experimental observations made in the range of $R_{M g / C a}$ rising from 0.5 to 7 at $\gamma_{\text {cal }}=0.5$ (Fig. 1). On the other hand, when $J$ is kept low and $\Lambda_{i}<100 \%$, increasing supersaturation does not change the conditions of $\varpi / v_{s}>1$ because $\varpi$ scales with $10^{1 / 2 \gamma_{c a l}}$ whereas $v_{s}$ scales with $\left(10^{1 / 2 \gamma_{c a l}}-1\right)$ (Eqs. 3 and 4$)$, indicating a continuous occurrence of preferential $\mathrm{Mg}$ adsorption/incorporation at the acute steps and consistent with the observations made at conditions of $0.5<\gamma<1.2$ when $R_{M g / C a}$ was kept constant at $=0.5$.

Now consider the cases where both the solution supersaturation and the cation ratio vary. Whereas increasing $\gamma_{c a l}$ leads to a faster increase in $\varpi$ than in $v_{s}$ (Eqs. 3 and 4) and hence a stronger incorporation of $\mathrm{Mg}$ in all growth fronts, higher $R_{\mathrm{Mg} / \mathrm{Ca}}$ intensifies $\mathrm{Mg}$ surface coverage and ultimately triggers the saturation of $\mathrm{Mg}$ at the acute steps, i.e. $\Lambda_{\text {acute }} \approx 100 \%$. The development of this condition now forces $\mathrm{Mg}$ to adsorb at the less favored sites (in our case the obtuse steps). This explains the development of type II morphology in solutions of higher $\gamma_{c a l}$ and $R_{M g / C a}$. Still, due to the inequality of $\tau_{-}>\tau_{+}$, the incorporation of Mg remains more substantial in the acute orientations, as indicated by the more severe step rounding shown in experimental observations (Fig. 1b).

\section{Type III morphology}

\section{1 plastic deformation and maximal Mg substitution}


Consistent with an earlier report [Sethmann, I., Wang, J. W. et al. 2010], our data also indicated the existence of a minimal level of $\gamma_{c a l}$ and $R_{M g / C a}$ for the development of surface segmentation. The minimal supersaturation and cation ratio revealed by our experiments were $\gamma_{\text {cal }} \approx 0.7$, or $\Omega_{\text {calcite }} \approx 5\left(\Omega\right.$ is defined as $\left.10^{\gamma_{c a l}}\right)$ and $R_{M g / C a} \approx 1$, lower than that of $\Omega_{c a l} \approx 33$ and $R_{M g / C a} \approx 2$ suggested by the data from [Sethmann, I., Wang, J. W. et al. 2010]. This difference could be due to the solution chemistry effects reported previously by [Hong, M. and Teng, H. H. 2014] given that our solutions had fixe $\mathrm{pH}$ (8.0), ionic strength (0.1) and $R_{M g / C a}(1.0)$ while the Sethmann's study had varied values in these parameters. Because of the mutual dependence between the minimal $R_{M g / C a}$ and $\gamma_{c a l}$ required for type III morphology development (Fig. 3), the supersaturation of dolomite $\gamma_{d o l}$ (Eq. 2) becomes a more intuitive and composite indicator to signal the morphology change even through dolomite is not formed in the experiments. For instance, at the opposite ends of our experimental conditions, $\gamma_{c a l}=$ 0.5 and $R_{M g / C a}=7$, and $\gamma_{c a l}=1.2$ and $R_{M g / C a}=0.5$, only type I morphology was observed because these conditions were associated with lower $\gamma_{c a l}(1.98$ and 2.22, respectively). On the other hand, a modest condition of $\gamma_{c a l}=0.9$ and $R_{M g / C a}=3$ brought about the full development of type III morphology when $\gamma_{\text {dol }}$ reached 2.41. A value of $\gamma_{d o l} \approx 2.39$ appears to be a reasonably accurate demarcation for the onset of type III morphology.

The existence of such a minimum suggests that the development of segmented surfaces with mosaic-like morphology probably results from the lattice stress buildup in calcite due to $\mathrm{Mg}$ for $\mathrm{Ca}$ substitution surpassing a certain threshold value. In agreement with Sethmann et al.'s observation, in situ AFM images from our experiments showed the 
occurrence of monolayers buckling to form intra-layer ridges along calcite cleavage directions (Fig. 2d). Moreover, our data also revealed an abrupt aggregation of steps in association with the rupture of curvature (Fig. 2d) at the onset of type III morphology. Whereas molecular dynamics modeling in Sethmann et al.'s study suggests a correlation between lattice relaxation and surface bulging, suffice to say that lattice deformation in the form of either layer buckling or step aggregation/curvature breakup results in the release of stress.

The $\mathrm{Mg}^{2+}$ ion $(0.86 \AA)$ is about $30 \%$ smaller than $\mathrm{Ca}^{2+}(1.14 \AA)$ in ionic radius [Shannon, R. D. 1976]. As a consequence, the $d_{104}$ value in the Mg-substituted calcite decreases constantly with increase $\mathrm{MgCO}_{3} \%$ [Zhang, F. F., Xu, H. F. et al., 2010]. Due to the size difference, a spherical local compressive stress field will be generated within monomolecular layers upon $\mathrm{Mg}^{2+}$ substitution of $\mathrm{Ca}^{2+}$ in calcite lattice. It is reasonable to assume that the stress can build up initially but will be released through plastic strain (i.e. permanent deformation) once the stress surpasses the elastic limit of calcite with increasing $\mathrm{Mg}$ presence. The minimal concentration of $\mathrm{Mg}$ in the lattice required for plastic strain to occur may be determined theoretically by comparing the elastic limit and the bulk modulus of calcite. A $b$ initio calculation of Mg-substituted calcite [Elstnerova, P., Friak, M. et al. 2010] gives a volume change of $18.36 \AA^{3}$ for the replacement of a Ca by a $\mathrm{Mg}$ in a calcite unit cell with dimensions of $383.56 \AA^{3}$. Assuming a spherical volume with an initial radius of $R$, the Mg-substitution reduces the cell radius to be $0.984 R$. It then follows that the strain energy $U$ generated due to the volume decrease is the summation of work done by the compressive force over the entire spherical surface of the stress field associated with the decrease of the unit cell from $R$ to $0.984 R$ : 


$$
U=\int_{0}^{4 \pi R^{2}} \sigma d s \int_{R}^{0.984 R} d r=-0.064 \pi \sigma R^{3}
$$

where $\sigma$ is the stress. On the other hand, [Elstnerova, P., Friak, M. et al. 2010] also indicated a calcite formation energy change of 0.05 ev/atom resultant from the $\mathrm{Mg}$ for $\mathrm{Ca}$ substitution, allowing one to obtain from (Eq. 5) a value of $1.37 \mathrm{GPa}$ for $\sigma$, which further leads to the determination of the ratio of stress to relative volume change upon the substitution of a Ca by a $\mathrm{Mg}$, i.e. $\sigma /\left(\frac{\Delta V}{V}\right)=28.62 \mathrm{GPa}$. Using either the experimental [Pavese, A., Catti, M. et al. 1996] or theoretical [Elstnerova, P., Friak, M. et al. 2010] value of 70.13 and 70.3 , respectively, for the bulk modulus of calcite, one finds that the minimal number of substitution of $\mathrm{Mg}$ for $\mathrm{Ca}$ in a calcite unit cell (6 formula units) before plastic deformation is around 2.4 , or $\sim 40 \%$.

\subsection{Mechanistic consideration}

In the presence of impurities or doping agents, mismatches can occur at the growth front of individual epi-layers subject to two lattice periodicities, that of the existing monolayer and that of the substrate. These mismatches may be accommodated by misfit strain (MS) or misfit dislocations (MD) with the latter often entering at some critical threshold strain levels [Matthews J. W. and Blakeslee, A. E. 1974; van der Merwe, J. H., 1991; Vdovin, V. I., 1999]. In the present study, misfits develop both horizontally (within a growing layer between the existing $\mathrm{CaCO}_{3}$ and the newly grown $(\mathrm{Ca}, \mathrm{Mg}) \mathrm{CO}_{3}$ domains), and vertically between the calcite substrate and the overlaying $\mathrm{Mg}$-containing calcium carbonate. When $\mathrm{Mg}$ content is low, as in the case of type I and II morphology, the growth morphology is modified by the gradual buildup of MS as indicated by the progressively loss of step directions. With increasing $\mathrm{Mg}$ incorporation, $\mathrm{MD}$ breaks in leading to the appearance of type III morphology. 
A critical issue for the development of type III morphology is the restoration of the original cleavage directions on the growing surfaces at the onset of MDs. A point defect is created in the lattice when a $\mathrm{Ca}$ is replaced by a $\mathrm{Mg}$. If these defects immediately produce MDs at steps (i.e. edge dislocation), a surface pattern (MD networks) in the epitaxial hetero-layer will evolve into a mosaic structure (i.e. type III morphology), similar to that reported on the $\mathrm{Si}_{1-\mathrm{x}} \mathrm{Ge}_{\mathrm{x}} / \mathrm{Si}$ system where $\mathrm{SiGe}$ was grown epitaxially on Si [Vdovin, V. I., 1999]. In our study, however, the defects initially only produced MS that transformed the straight steps in calcite to curved ones in the resultant magnesian calcite, and MDs did not come into play until a later stage when $\mathrm{Mg}$ content was high. A reasonable mechanism to explain the timing of MD occurrence may be defect diffusion. It is well known that point defects are mobile and move stochastically in lattices following Fick's diffusion law (e.g. [Antoniadis, D. A. and Moskowitz, I. 1982; Gremaud, G., Ho, L. P. et al. 1983; Hwang, I. S., Theiss, S. K. et al. 1994; Libal, A., Reichhardt, C. et al. 2007]). More importantly, it was documented that point defects tend to exhibit surprising memory effects and diffuse along certain easy directions [Pertsinidis, A. and Ling, X. S. 2001]. It is conceivable, from an energetics point of view, that the $\mathrm{Mg}$ sites, that is, the point defects in our case, will ultimately align themselves along the most stable directions (i.e. calcite $[\overline{4} 41]$ ) to release the accumulated misfit stress, leading to the nucleation of linear MDs. If and when this occurs, the local Mg concentration may reach the theoretical maximum of $\sim 40 \%$, and the individual spherical stress field associated with each point defect will coalesce to give rise to a cylindrical field along the low energy direction (Fig. 4). This is because, whereas the $\sigma_{y y}$ component (i.e. parallel to the alignment) of individual stress fields around each $\mathrm{Mg}$ site will largely cancel out, the $\sigma_{x x}$ 
components overlap to produce a stronger compressive force perpendicular to the alignment directions and ultimately cause monolayer buckling. Furthermore, if the linear field is near steps, the $\sigma_{z z}$ components may lead to attractive stress between layers to cause steps to bunch or aggregate [Schindler, A. C., Gyure, M. F. et al. 2003]. In both cases, the resultant ridges or macro-steps, now following the original calcite cleavage directions, should have a lower surface energy than the curved steps.

\subsection{Implications for the dolomite problem}

Complete inhibition of monolayer growth was never observed in the full range of our experimental conditions ( $\gamma_{c a l}$ from 0.5 to $1.2 ; R_{M g / C a}$ from 0.5 to 7 ) prior to the formation of surface ridges in type III morphology. Even within the 'mosaic-like' tiles on the segmented surfaces, curved steps of individual layers still advance at detectable speeds (Fig. 2c). Rather, it is the emergence of the surface ridges that finally stops the growth process as the advance of all individual steps comes to an end upon reaching the segmentation boundaries. We surmise that the magnesium concentration in these ridges probably has reached the maximal value $(\sim 40 \%)$ calculated from the stress-strain consideration. If this is the case, the observation may imply that the inhibition of $\mathrm{Mg}$ to calcite growth and the difficulty of dolomite formation at ambient conditions are ultimately attributed to the lattice stress buildup originated from the continuous substitution of $\mathrm{Mg}$ for $\mathrm{Ca}$. That is, lattice distortion at $\sim 40 \% \mathrm{Mg}$ presence is so severe that further growth cannot proceed. The threshold value of $\sim 40 \% \mathrm{Mg}$ calculated in this study is in fact in good agreement with the HRTEM measurements in modern protodolomite $\left(\mathrm{MgCO}_{3} \% \sim 40\right.$ to 44\%) [Xu, H. F., 2010] and synthetic disordered dolomite $\left(\mathrm{MgCO}_{3} \% \sim 45 \%\right)$ [Zhang, F. F., Xu, H. F. et al., 2010], and with the composition of the 
$(\mathrm{Ca}, \mathrm{Mg}) \mathrm{CO}_{3}$ phase synthesized in anhydrous conditions (amorphous precipitate when $\mathrm{Mg}>\sim 37 \%$ ) [Xu, J., Yan, C. et al. 2013]. It is important to note that, whereas $\sim 40 \% \mathrm{Mg}$ is needed to induce the ridge structure formation to completely stop growth at monolayer level, less than $20 \%$ may be enough to render bulk growth unnoticeable given the widely reported observation that, in the absence of additives or biological activities, $\mathrm{Mg}$ content in ambient laboratory grown $(\mathrm{Mg}, \mathrm{Ca}) \mathrm{CO}_{3}$ phases never exceeded 20\% [Mucci, A. and Morse, J. W. 1983; Mucci, A. 1986; Sethmann, I., Wang, J. W. et al. 2010; Zhang, F. F., Yan, C. et al. 2013].

\section{CONCLUSION}

We investigated the evolution of growth morphology on the cleavage surfaces of calcite with changing $\mathrm{Mg}$ to $\mathrm{Ca}$ ratios and supersaturation in the solutions, and found three types of morphological variations. When either $R_{\mathrm{Mg} / \mathrm{Ca}}$ or $\gamma_{\mathrm{cal}}$ is low, step rounding in the acute side was observed; increased $\mathrm{Mg}$ concentration and supersaturation first engendered morphological changes in both the acute and the obtuse directions, followed by the development of monolayer buckling and step aggregation in the original cleavage direction to form surface segmentation, indicating $\mathrm{Mg}$ effects propagating from one dimension (individual crystallographic directions) to two dimensions (i.e. the entire growth surface). These observations suggest that the morphological evolution is controlled by a combined effect of solution $\mathrm{Mg}$ flux and step kinetics, and may result from the lattice stress buildup derived from cation substitution. We propose that, at low $R_{M g / C a}$ or $\gamma_{c a l}$ conditions, the $\mathrm{Mg}$ effect is governed by the relative rate of $\mathrm{Mg}$ attachment at kinks relative to step speed. Increasing $\mathrm{Mg}$ concentration and 
supersaturation ultimately leads to a significant presence of point defects in association with the extensive substitution of $\mathrm{Mg}$ for $\mathrm{Ca}$. We further propose that the diffusion and the resultant alignment of these defects are responsible for the release of lattice stress in the form of plastic deformation (monolayer buckling and step aggregation) observed in high $R_{M g / C a}$ and $\gamma_{c a l}$ solutions. Calculations indicate that the $\mathrm{Mg}$ content needed to generate lattice stress exceeding the elastic limit of calcite is around $\sim 40 \%$, beyond which growth comes to a complete stoppage at the monolayer level. This result suggests that the excessive lattice stress due to the size difference in $\mathrm{Mg}$ for $\mathrm{Ca}$ may be the ultimately cause for Mg inhibiting calcite growth and for the lack of dolomite formation in ambient conditions.

\section{ACKNOWLEDGMENTS}

This research was supported by the Basic Energy Science of US DOE through Grant DE-FG02-02ER15366. 


\section{REFERENCE}

Althoff, P. L. (1977) Structural refinements of dolomite and a magnesian calcite and implications for dolomite formation in marine-enviroment. American Mineralogist 62(7-8), 772-783.

Antoniadis, D. A. and Moskowitz, I. (1982) Diffusion of substitutional impurities in silicon at short oxidation times - an insight into point - defect kinetics. Journal of Applied Physics 53(10), 6788-6796.

Arvidson, R. S., Collier, M., Davis, K. J., Vinson, M. D., Amonette, J. E. and Luttge, A. (2006) Magnesium inhibition of calcite dissolution kinetics. Geochimica Et Cosmochimica Acta 70(3), 583-594.

Astilleros, J. M., Fernandez-Diaz, L. and Putnis, A. (2010) The role of magnesium in the growth of calcite: An AFM study. Chemical Geology 271(1-2), 52-58.

Barker, S., Greaves, M. and Elderfield, H. (2003) A study of cleaning procedures used for foraminiferal Mg/Ca paleothermometry. Geochemistry Geophysics Geosystems 4.

Berner, R. A. (1975) Role of magnesium in crystal-growth of calcite and aragonite from seawater. Geochimica Et Cosmochimica Acta 39(4), 489-\&.

Bischoff, W. D., Bishop, F. C. and Mackenzie, F. T. (1983) Biogenically produced magnesian calcite inhomogeneities in chemical and physical-properties comparison with synthetic phases. American Mineralogist 68(11-1), 1183-1188.

Botsaris, G. D., Mason, E. A. and Reid, R. C. (1967) Incorporation of ionic impurities in crystals growing from solution. The case of lead ions in potassium chloride crystals. AIChE J. 13, 764-768.

Burton, W. K., Cabrera, N. and Frank, F. C. (1951) The growth of crystals and the equilibrium structure of their surfaces. Philos. T. Roy. Soc. A.

Busenberg, E. and Plummer, L. N. (1989) Thermodynamics of magnesian calcite solid-solutions at 25-degrees-C and 1-atm total pressure. Geochimica Et Cosmochimica Acta 53(6), 1189-1208.

Chernov, A. A. (1961) Spiral growth of crystals. Sov Phys Uspekhi, Uspekhi Fiz Nauk 73, 277331.

Davies, C. W. (1962) Ion Association London, Butterworths.

Davis, K. J., Dove, P. M. and De Yoreo, J. J. (2000) The role of Mg2+ as an impurity in calcite growth. Science 290(5494), 1134-1137.

Davis, K. J., Dove, P. M., Wasylenki, L. E. and De Yoreo, J. J. (2004) Morphological consequences of differential $\mathrm{Mg} 2+$ incorporation at structurally distinct steps on calcite. American Mineralogist 89(5-6), 714-720.

De Yoreo, J. J., Land, T. A., Rashkovich, L. N., Onischenko, T. A., Lee, J. D., Monovskii, O. V., et al. (1997) The effect of dislocation cores on growth hillock vicinality and normal growth rates of KDP $\left\{\begin{array}{lll}1 & 0 & 1\end{array}\right\}$ surfaces. Journal of Crystal Growth 182(3-4), 442-460.

De Yoreo, J. J. and Vekilov, P. G. (2003) Principles of crystal nucleation and growth. Biomineralization. P. M. Dove, J. J. DeYoreo and S. Weiner. Washington, Mineralogical Soc America. 54 57-93.

De Yoreo, J. J., Zepeda-Ruiz, L. A., Friddle, R. W., Qiu, S. R., Wasylenki, L. E., Chernov, A. A., et al. (2009) Rethinking classical crystal growth models through molecular scale insights: consequences of kink-limited kinetics. Crystal Growth \& Design 9(12), 5135-5144.

Elstnerova, P., Friak, M., Fabritius, H. O., Lymperakis, L., Hickel, T., Petrov, M., et al. (2010) $\mathrm{Ab}$ initio study of thermodynamic, structural, and elastic properties of Mg-substituted crystalline calcite. Acta Biomaterialia 6(12), 4506-4512. 
Evans, D. W., Muller-Loennies, S., Brooks, C. L., Brade, L., Kosma, P., Brade, H., et al. (2012) BCSDB_record_ID_26190. Bacterial Carbohydrate Structure DataBase.

Falini, G., Gazzano, M. and Ripamonti, A. (1994) Calcite crystallization on gelatin films containing polyelectrolytes. Advanced Materials 6(1), 46-48.

Gayathri, S., Lakshminarayanan, R., Weaver, J. C., Morse, D. E., Kini, R. M. and Valiyaveettil, S. (2007) In vitro study of magnesium-calcite biomineralization in the skeletal materials of the seastar Pisaster giganteus. Chemistry-a European Journal 13(11), 3262-3268.

Given, R. K. and Wilkinson, B. H. (1985) Kinetic control of morphology, composition, and mineralogy of abiotic sedimentary carbonates Journal of Sedimentary Petrology 55(1), 109-119.

Glodsmith, J. R. and Graf, D. L. (1958) Relation between lattice constants and composition of the Ca-Mg carbonate. American Mineralogist 43, 84-101.

Goldsmith, J. R., Graf, D. L. and Heard, H. C. (1961) Lattice constants of the calciummagnesium carbonates. American Mineralogist 46, 453-459.

Gremaud, G., Ho, L. P. and Benoit, W. (1983) Interation mechanisms between dislocations, immobile point-defects and mobile point-defects in pure aluminum near the roomtemperature range. Journal De Physique 44(NC-9), 581-586.

Hong, M. and Teng, H. H. (2014) Implications of solution chemistry effects: Direction-specific restraints on the step kinetics of calcite growth. Geochimica Et Cosmochimica Acta 141, 228-239.

Hwang, I. S., Theiss, S. K. and Golovchenko, J. A. (1994) Mobile point-defects and atomic basis for structural transformations of a crystal-surface. Science 265(5171), 490-496.

King, H. E., Satoh, H., Tsukamoto, K. and Putnis, A. (2013) Nanoscale observations of magnesite growth in chloride- and sulfate-rich solutions. Environmental Science \& Technology 47(15), 8684-8691.

Konigsberger, E. and Gamsjager, H. (1992) Solid-solution aqueous-solution eauilibria thermodynamic theory and representation. American Journal of Science 292(3), 199-214.

Kulik, D. A. (2006) Dual-thermodynamic estimation of stoichiometry and stability of solid solution end members in aqueous-solid solution systems. Chemical Geology 225(3-4), 189-212.

Lear, C. H., Rosenthal, Y. and Slowey, N. (2002) Benthic foraminiferal Mg/Capaleothermometry: A revised core-top calibration. Geochimica Et Cosmochimica Acta 66(19), 3375-3387.

Libal, A., Reichhardt, C. and Reichhardt, C. J. O. (2007) Point-defect dynamics in twodimensional colloidal crystals. Physical Review E 75(1).

Lippmann, F. (1973) Sedimentary Carbonate Minerals New York, Springer.

Loste, E., Wilson, R. M., Seshadri, R. and Meldrum, F. C. (2003) The role of magnesium in stabilising amorphous calcium carbonate and controlling calcite morphologies. Journal of Crystal Growth 254(1-2), 206-218.

Matthews, J., W. and Blakeslee, A. E. (1974) Defects in epitaxial multilayers: I. Misfit dislocations. Journal of Crystal Growth 27, 118-125.

Meldrum, F. C. and Hyde, S. T. (2001) Morphological influence of magnesium and organic additives on the precipitation of calcite. Journal of Crystal Growth 231(4), 544-558.

Mucci, A. (1986) Growth - kinetics and composition of magnesian calcite overgrowths precipitated from seawater - quantitative influence of ortho-phosphate ions Geochimica Et Cosmochimica Acta 50(10), 2255-2265. 
Mucci, A. and Morse, J. W. (1983) The incorporation of $\mathrm{Mg} 2+$ and $\mathrm{Sr} 2+$ into calcite overgrowths - influences of growth - rate and solution composition Geochimica Et Cosmochimica Acta 47(2), 217-233.

Northrup, P. A. and Reeder, R. J. (1994) Evidence for the importance of growth-surface structure to trace-element incorporation in topaz. American Mineralogist 79(11-12), 1167-1175.

Paquette, J. and Reeder, R. J. (1990) New type of compositional zoing in calcite - insights into crystal - growth mechanisms. Geology 18(12), 1244-1247.

Paquette, J. and Reeder, R. J. (1995) Relationship between surface-structure, growth-mechanism, and trace-element incorporation in calcite. Geochimica Et Cosmochimica Acta 59(4), 735-749.

Parkhurst, D. L. and Appelo, C. A. J. (1999) User guide to PHREEQC (version 2) - A computer program for speciation, batch reaction, one dimensional transport, and inverse geochemical calculations. U.S. Geological Survey Water-Resources Investigation Report(99-4259).

Pavese, A., Catti, M., Parker, S. C. and Wall, A. (1996) Modelling of the thermal dependence of structural and elastic properties of calcite, $\mathrm{CaCO}_{3}$. Physics and Chemistry of Minerals 23(2), 89-93.

Pertsinidis, A. and Ling, X. S. (2001) Diffusion of point defects in two-dimensional colloidal crystals. Nature 413(6852), 147-150.

Pimentel, C., Pina, C. M. and Gnecco, E. (2013) Epitaxial growth of calcite crystals on dolomite and kutnahorite (104) surfaces. Crystal Growth \& Design 13(6), 2557-2563.

Reeder, R. J. (1996) Interaction of divalent cobalt, zinc, cadmium, and barium with the calcite surface during layer growth. Geochimica Et Cosmochimica Acta 60(9), 1543-1552.

Reeder, R. J. and Paquette, J. (1989) Sector zoning in natual and synthetic calcites. Sedimentary Geology 65(3-4), 239-247.

Schindler, A. C., Gyure, M. F., Simms, G. D., Vvedensky, D. D., Caflisch, R. E., Connell, C., et al. (2003) Theory of strain relaxation in heteroepitaxial systems. Physical Review B 67(7).

Sethmann, I., Wang, J. W., Becker, U. and Putnis, A. (2010) Strain-induced segmentation of magnesian calcite thin films growing on a calcite substrate. Crystal Growth \& Design 10(10), 4319-4326.

Shannon, R. D. (1976) Revised effective ionic-radii and systematic studies of interatomic distances in halides and chalcogenides. Acta Crystallographica Section A 32(SEP1), 751767.

Stephenson, A. E., DeYoreo, J. J., Wu, L., Wu, K. J., Hoyer, J. and Dove, P. M. (2008) Peptides enhance magnesium signature in calcite: Insights into origins of vital effects. Science 322(5902), 724-727.

Tang, Y. Z., Elzinga, E. J., Lee, Y. J. and Reeder, R. J. (2007) Coprecipitation of chromate with calcite: Batch experiments and X-ray absorption spectroscopy. Geochimica Et Cosmochimica Acta 71(6), 1480-1493.

van der Merwe, J. H. (1991) Misfit dislocation generation in epitaxial layers. Critical Reviews in Solid State and Materials Sciences 17(3), 187-209.

Vdovin, V. I. (1999) Misfit dislocations in epitaxial heterostructures: mechanisms of generation and multiplication. Physica Status Solidi (a) 171, 239-250.

Wasylenki, L. E., Dove, P. M. and De Yoreo, J. J. (2005) Effects of temperature and transport conditions on calcite growth in the presence of $\mathrm{Mg} 2+$ : Implications for paleothermometry. Geochimica Et Cosmochimica Acta 69(17), 4227-4236. 
Xu, H. F. (2010) Synergistic roles of microorganisms in mineral precipitates associated with deep sea methane seeps. In Larry L. Barton, Martin Mandl and Alexander Loy (Editors) Geomicrobiology: Molecular and Environmental Perspective, p. 325-346. Springer.

Xu, J., Yan, C., Zhang, F. F., Konishi, H., Xu, H. F. and Teng, H. H. (2013) Testing the cationhydration effect on the crystallization of $\mathrm{Ca}-\mathrm{Mg}-\mathrm{CO} 3$ systems. Proceedings of the National Academy of Sciences of the United States of America 110(44), 17750-17755.

$\mathrm{Xu}, \mathrm{M}$. and Higgins, S. R. (2011) Effects of magnesium ions on near-equilibrium calcite dissolution: Step kinetics and morphology. Geochimica Et Cosmochimica Acta 75(3), 719-733.

Zhang, F. F., Yan, C., Teng, H. H., Roden, E. E. and Xu, H. F. (2013) In situ AFM observations of $\mathrm{Ca}-\mathrm{Mg}$ carbonate crystallization catalyzed by dissolved sulfide: Implications for sedimentary dolomite formation. Geochimica Et Cosmochimica Acta 105, 44-55.

Zhang, F. F., Xu, H. F., Konishi, H., and Roden, E. E. (2010) A relationship between d-104 value and composition in the calcite - disordered dolomite solid solution series. American Mineralogist, 95 (11-12), 1650-1656.

Zhang, Y. P. and Dawe, R. A. (2000) Influence of Mg2+ on the kinetics of calcite precipitation and calcite crystal morphology. Chemical Geology 163(1-4), 129-138. 


\section{CAPTIONS}

Fig 1. Summary of calcite surface morphologies in solutions of different compositions depicted by calcite supersaturation (x-axis) and $\mathrm{Mg}$ to $\mathrm{Ca}$ raio (y-axis). Images on the left side of the zigzag line are types I and II morphologies whereas on the right side is type III. Literature data from Davis et al. (2004) and Sethamann et al. (2010) are also included for reference.

Fig 2. AFM images of calcite growth spirals at differnet levels of supersaturation and $a_{M g^{2+}} /$ $a_{C a^{2+}}$. All images are oriented with the obtuse side on the top and acute side on the bottom as marked in (a). In type I morphology (a), only the acute steps on the growth spiral are affected and rounded in the presence of $\mathrm{Mg}$ while the obtuse ones remain straight and maintain their original crystallographic directions. In type II morphology (b), both obtuse and acute steps are rounded although the change in acute side appears to be more severe as the steps have completely lost their growth directions. Type III morphology (c) exhibits a segmented surface where individual sections are bordered by multi-layer thick ridges oriented in the original cleavage directions. No detectable movement is observed at these riges, but monolayers with rounded edges continue to grow inside the individual segments. The transition from type II to type III morphology (d) is characterized by a snapping of curves steps into straight segments followed by step aggregation upsteam (arrow 1), or a suddent buckling of terraces that cuts through multiple steps (arrow 2). Both the snapping and the buckling lead to the formation of ridges parallel to the original calcite $<\overline{4} 41>$ directions.

Fig 3. Inverse relation between calcite supersatguration (x-axis) and solution $\mathrm{Mg}^{2+}$ concentration requried for the development of type III morpholoy. Dash line indicates the minimum conditions separating type III morphology from type and type II.

Fig 4. Schematics showing the occurrence of point defects in calcite due to $\mathrm{Mg}$ (small green spheres) substitution of $\mathrm{Ca}$ (large red spheres) and resultant individual compressive stress field (a). Upon diffusion, these point defects may align themselves in a low energy direction (parallel to y-axis) and subsequently produce a cylindrical compressive stress field (b). The compress stress (parallel to $\mathrm{x}$-axis) can be released through layer buckling that forms a ridge parallel to the y-axix. 




Fig. 1 

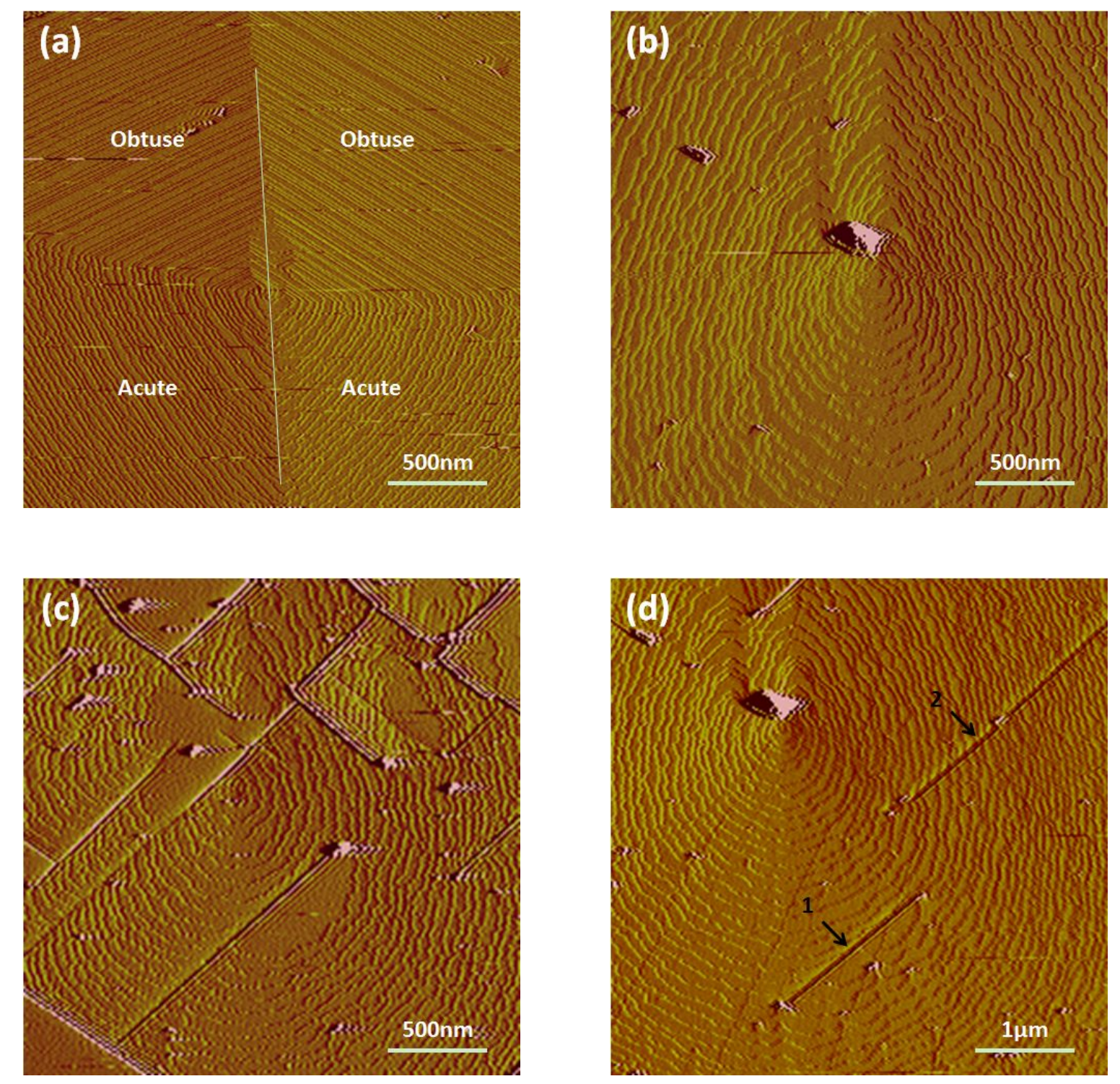

Fig. 2 


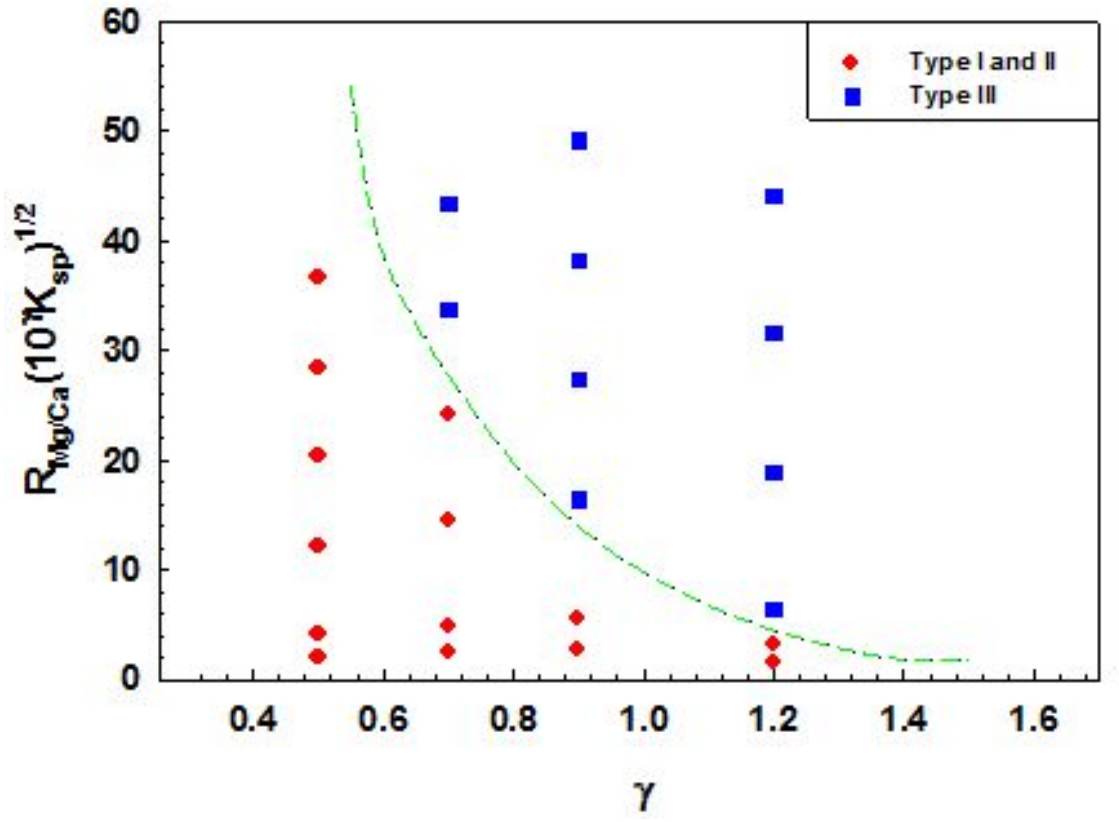

Fig. 3 

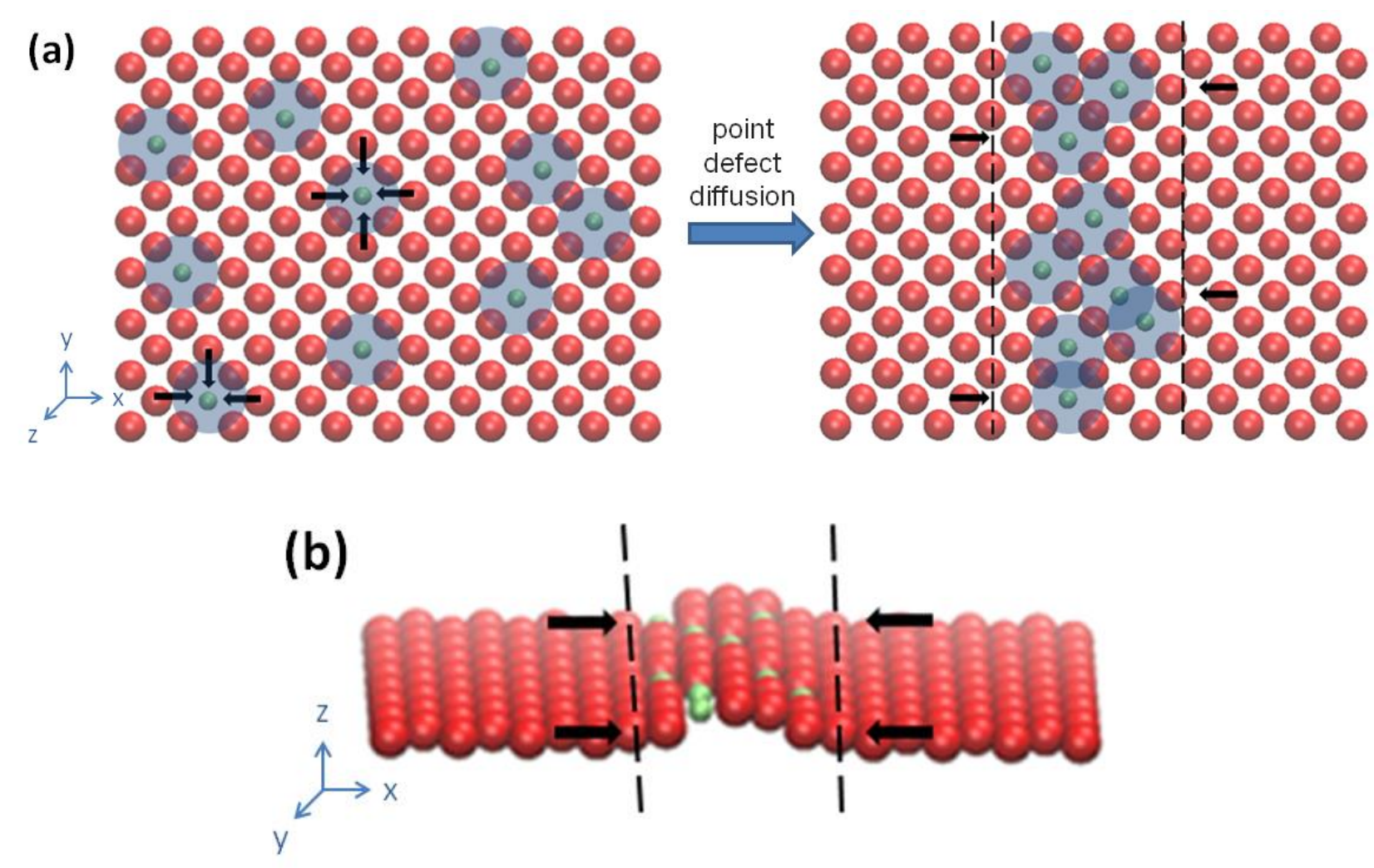

Fig. 4 